\title{
Green synthesis and characterization of silver nanoparticles by leaf extracts of Cycas circinalis, Ficus amplissima, Commelina benghalensis and Lippia nodiflora
}

\author{
I. Johnson • H. Joy Prabu
}

Received: 17 September 2014/ Accepted: 15 December 2014/Published online: 14 January 2015

(C) The Author(s) 2015. This article is published with open access at Springerlink.com

\begin{abstract}
Biosynthesis of nanoparticles is a kind of bottom-up approach where the main reaction occurring is reduction. Since silver nanoparticles (AgNPs) have been used for infection prevention in medical field, it is more relevant to reduce their size using ancient Indian herbal plants. This method is good in anti-microbial efficiency against bacteria, viruses and other microorganisms and hence clearly enhances the medicinal usage of AgNPs. This type of green biosynthesis of nanoparticles has received increasing attention due to the growing need to develop safe, cost-effective and environmental-friendly technologies for nano-materials synthesis. In the process of synthesizing AgNPs, we observed a rapid reduction of silver ions leading to the formation of stable crystalline AgNPs in the solution. Plant extracts from Cycas circinalis, Ficus amplissima, Commelina benghalensis and Lippia nodiflora were used for the synthesis of AgNPs from silver nitrate solution. AgNPs were characterized by different techniques.
\end{abstract}

Keywords Silver nanoparticles - Green synthesis · Bioreduction · Plant extracts · FTIR · UV analysis . SEM and XRD analyses

\section{Introduction}

Due to the unique size-dependent physical and chemical properties, nanostructured materials have been the focus of intense research in recent decades [1]. Since the particle size can be tailored readily from 1 to $100 \mathrm{~nm}$ in diameter with

I. Johnson $(\bowtie) \cdot$ H. J. Prabu

Department of Physics, St. Joseph's College, Centre for Nano sciences and Applied Thermodynamics, Trichy 620002, India e-mail: jnaadarsh@hotmail.com moderate to excellent control over size uniformity, the resulting novel properties of these materials have been used for various optical [2] and electrical [3] applications. The applications include nano-electronics, photonic crystals and sensors based on surface enhanced Raman scattering [4] and near-field microscopy. Biosynthesis of nanoparticles is a kind of bottom-up approach where the main reaction occurring is reduction. The need for biosynthesis of nanoparticles rose because the physical and chemical processes were not ecofriendly. Often chemical synthesis method leads to the presence of some of the toxic chemicals absorbed on the surface that may have adverse effect in the medical applications.

This is not an issue when it comes to biosynthesized nanoparticles via green synthesis route. So, in the search of cheaper pathways for nanoparticles synthesis, scientists used microbial enzymes and plant extracts (phytochemicals). With their antioxidant or reducing properties, they are usually responsible for the reduction of metal compounds into their respective nanoparticles [5]. In the present work, we have proposed for the first time the results of a green synthesis method for AgNP, using Cycas circinalis, Ficus amplissima, Commelina benghalensis and Lippia nodiflora extracts as a reducing and stabilizing agent. Bioreduction mechanism of these extracts for the synthesis of silver nanoparticles (AgNPs) was investigated through visual examination (color change), UV absorption techniques, FTIR, SEM and XRD analyses (Table 1).

\section{Materials and methods}

Plant leaves

For the synthesis of AgNPs, C. circinalis, F. amplissima, $C$. benghalensis and L. Nodiflora were collected from the 
Table 1 Assignments of IR band frequencies $\left(\mathrm{cm}^{-1}\right)$ of AgNP's

\begin{tabular}{ll}
\hline Vibrational assignment & Vibrational frequencies $\left(\mathrm{cm}^{-1}\right)$ \\
\hline Amide I band & 1,636 \\
& 1,639 \\
& 1,636 \\
& 1,637 \\
Silver metal vibrations & 693.55 \\
& 670.48 \\
& 670.81 \\
& 594.14
\end{tabular}

forest near Kallanai, South India. A photograph of plants is shown in Fig. 1. The extract was used as reducing and capping agent [6]. Silver nitrate and ethanol were purchased from Sigma Aldrich, Germany.

Medicinal importance of the plants under study

\section{Cycas circinalis}

The spongy white tissue lining (pith) has medicinal values and an extract of the pith is used to increase milk production in lactating mothers. Powder of male gametes is used for narcotic. Uttermost layers of stems and roots of the plant are used as oil and it is applied with a cloth on the body to relieve swelling and other inflammation [7].

\section{Ficus amplissima}

Ficus Amplissima is used in Ayurveda, Siddha and Unani herbal medicinal preparations in India. It is useful for the treatment of diabetes. The extract from the layer of stems and roots can reduce blood glucose levels. It also increases serum insulin and body weight. Extract of leaves exhibited better anti-inflammatory, wound healing and antioxidant activity [8].

\section{Commelina benghalensis}

The leaves, root and whole plant of $C$. Benghalensis are medicinally useful. The plant is useful for softening the skin, relieving inflammation or irritation, stimulating or facilitating evacuation of the bowels and beneficial in leprosy [9].

\section{Lippia nodiflora}

The whole plant is useful for knee joint pain, urinary retention, kidney disease and fever. The extract is useful for diet and kidney (renal) stoners [10].
Preparation of leaf extract

The extract was made using $20 \mathrm{~g}$ of fresh leaves. Prior to extract preparation, the plant leaves were cleaned thoroughly using deionized water and then cut into small pieces. The plant extract sample was then added into $125 \mathrm{ml}$ of boiling deionized water, and left to boil for $3 \mathrm{~min}$. The solution was then removed from the heat source and left to cool to ambient temperature (approximately $25^{\circ} \mathrm{C}$ ). The extract was then filtered through a coarse sieve to remove any leaf matter and the resultant filtrate was then refrigerated. The Plant extract was collected and stored at $4{ }^{\circ} \mathrm{C}$. Finally, the extract was used for the synthesis of AgNPs [11].

\section{Synthesis of silver nanoparticles}

The silver nitrate $\left(\mathrm{AgNO}_{3}\right)$ used in this experiment was obtained from Sigma Aldrich. $3 \mathrm{ml}$ of Plant extract was added to $60 \mathrm{ml}$ of $10^{-3} \mathrm{M} \mathrm{AgNO}_{3}$ solution and the reaction was left to take place at ambient conditions [12]. The observed change in color from colorless to transparent yellow and finally to a dark brown with time indicates the formation of AgNPs.

Reduction of the $\mathrm{Ag}+$ ions was monitored with respect to time using UV-visible spectral analysis. Once the reaction mixture reached a dark brown color, it was then centrifuged to collect the AgNPs. The nanoparticles have been washed three times using deionized water, and were then re-suspended in $95 \%$ ethanol (Fisher Scientific) prior to characterization. The $\mathrm{pH}$ value of the green synthesis of nanoparticles has been maintained at 9 .

\section{Centrifuge method}

Centrifuged technique was used to separate the nanoparticles from the solution $\left(\mathrm{AgNO}_{3}+\right.$ plant extract). The solution was centrifuged at 3,000 rpm for $10 \mathrm{~min}$. The centrifuged supernatant liquid was collected and then centrifuged twice at $10,000 \mathrm{rpm}$ for $30 \mathrm{~min}$. The suspended pellet was purified using ethanol [13]. The purified pellets were then dried and the powder was taken which is used for further characterization.

Sonication

The collected AgNPs were brought inside a small beaker and distilled water was added. The beaker was kept in sonicator for $10 \mathrm{~min}$ and then the nanoparticles were collected in petri plate.

Hot air oven

Silver nanoparticles were kept inside the oven at a temperature of $200{ }^{\circ} \mathrm{C}$ for $4 \mathrm{~h}$. After the evaporation of ethanol and 


\section{[i] Cycas Circinalis:}

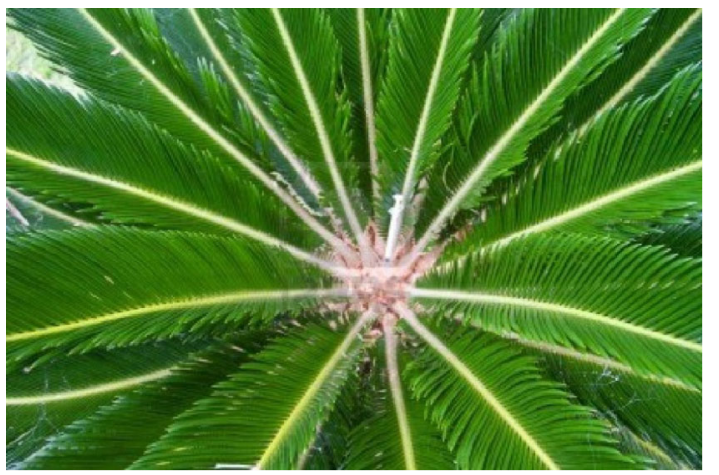

Botanical name

Tamil name

English name

Genus

[iii] Commelina Benghalensis:

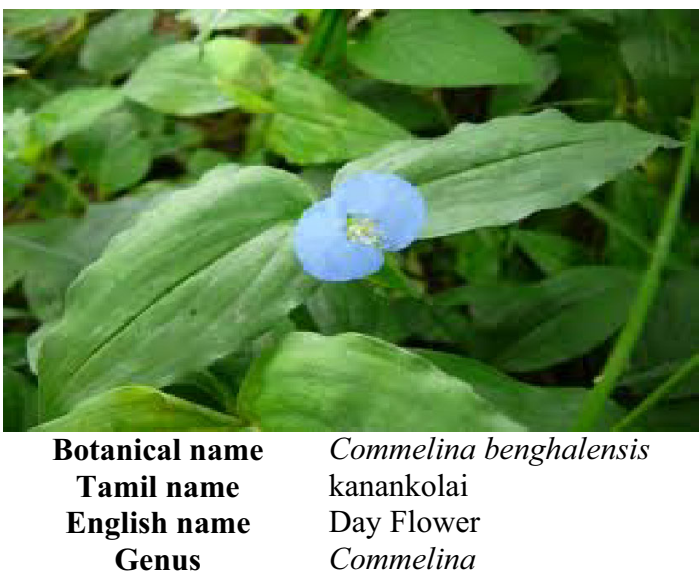

\section{[ii] Ficus Amplissima:}

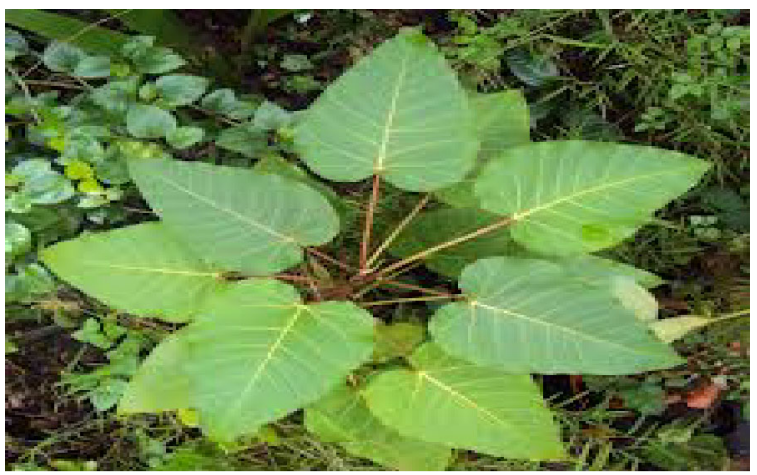

Botanical name

Tamil name

Ficus Amplissima

ichi

English name

Genus

Cluster Fig Tree

Ficus

\section{[iv] Lippia Nodiflora:}

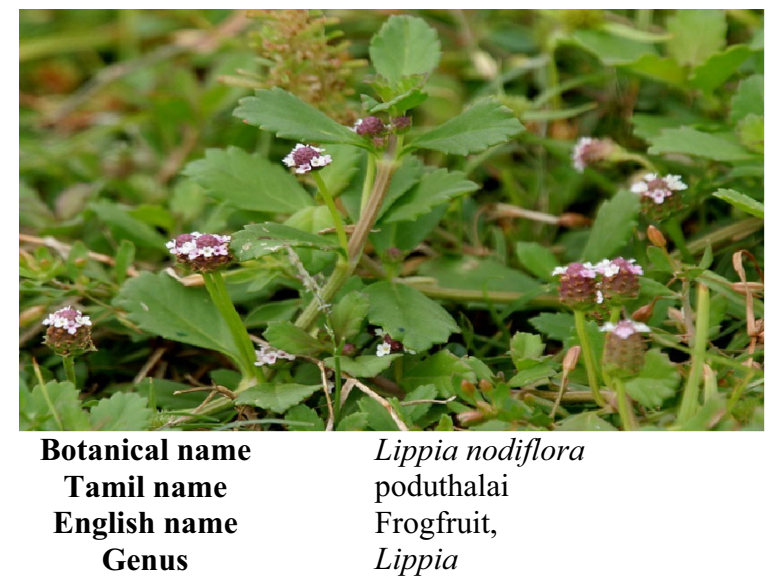

Fig. 1 Photographs of Cycas circinalis, Ficus amplissima, Commelina benghalensis and Lippia nodiflora

water molecules, the nanoparticles have been collected in powder form. The following chart shows the flow of various techniques to get fine nanoparticles.

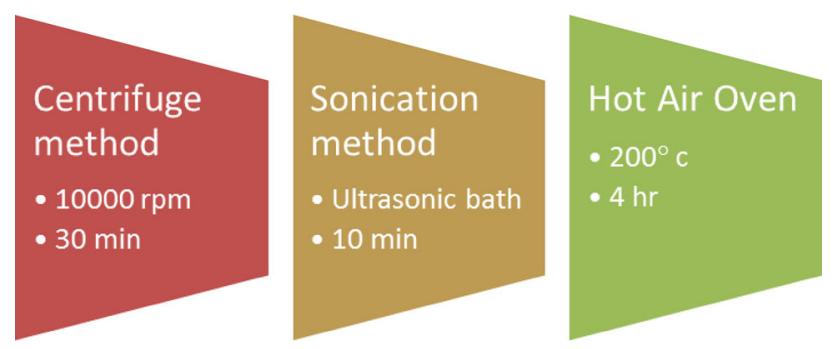

Characterization

\section{Color change}

The color change of reaction mixture (silver nitrate solution and leaf extract) with respect to time is observed. The color changes at $15 \mathrm{~min}$ from colorless to faint yellow, indicating the formation of AgNPs. As time elapsed, the yellow-colored solution eventually became dark brown at $120 \mathrm{~min}$, which is due to the increasing concentration of AgNPs as well as the growth of the particles in size. There is no significant change beyond $180 \mathrm{~min}$, indicating the completion of the reduction reaction. This was further confirmed by UV-Vis spectroscopic analysis [14]. 


\section{UV-Vis spectra analysis}

The reduction of pure silver ions was observed by measuring the UV-Vis spectrum of the reaction at different time intervals taking $1 \mathrm{ml}$ of the sample, compared with $1 \mathrm{ml}$ of distilled water used as blank [15]. UV-Vis spectral analysis has been done using Perkin-Elmer Lambda 25 spectrophotometer.

\section{FTIR analysis}

The FTIR spectrum was recorded in the range of $4,000-400 \mathrm{~cm}^{-1}$ at a resolution of $4 \mathrm{~cm}^{-1}$ using PerkinElmer spectrometer. The sample was mixed with $\mathrm{KCl}$ procured from Sigma. Thin sample disc was prepared and placed in fourier transform infrared (FTIR) for the analysis of the nanoparticles [16].

\section{SEM analysis}

After preparing the nanoparticles, the suspension of nanoparticles in water was used for SEM analysis by fabricating a drop of suspension into a clean electric stub and allowing water to completely evaporate. SEM observations were carried out on a ZEISS EVO 40 EP Electron microscope [17].

\section{XRD analysis}

The synthesized nanoparticles were subjected to X-ray diffraction using PW3710 based Philips analytical powder $\mathrm{X}$-ray diffractometer [18].

\section{Plant Name: Cvcas Circinalis}

(A) Color Change

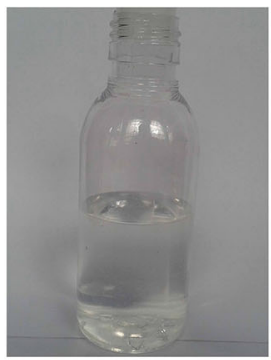

0 Min

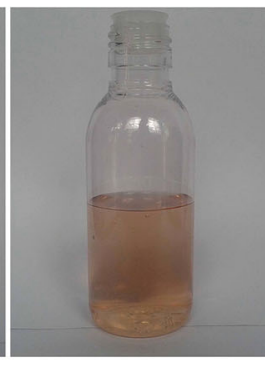

30 Min

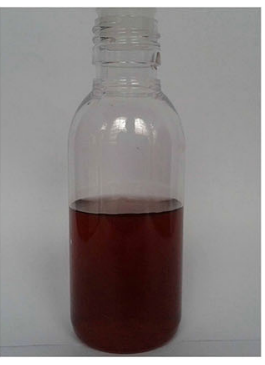

$180 \mathrm{Min}$
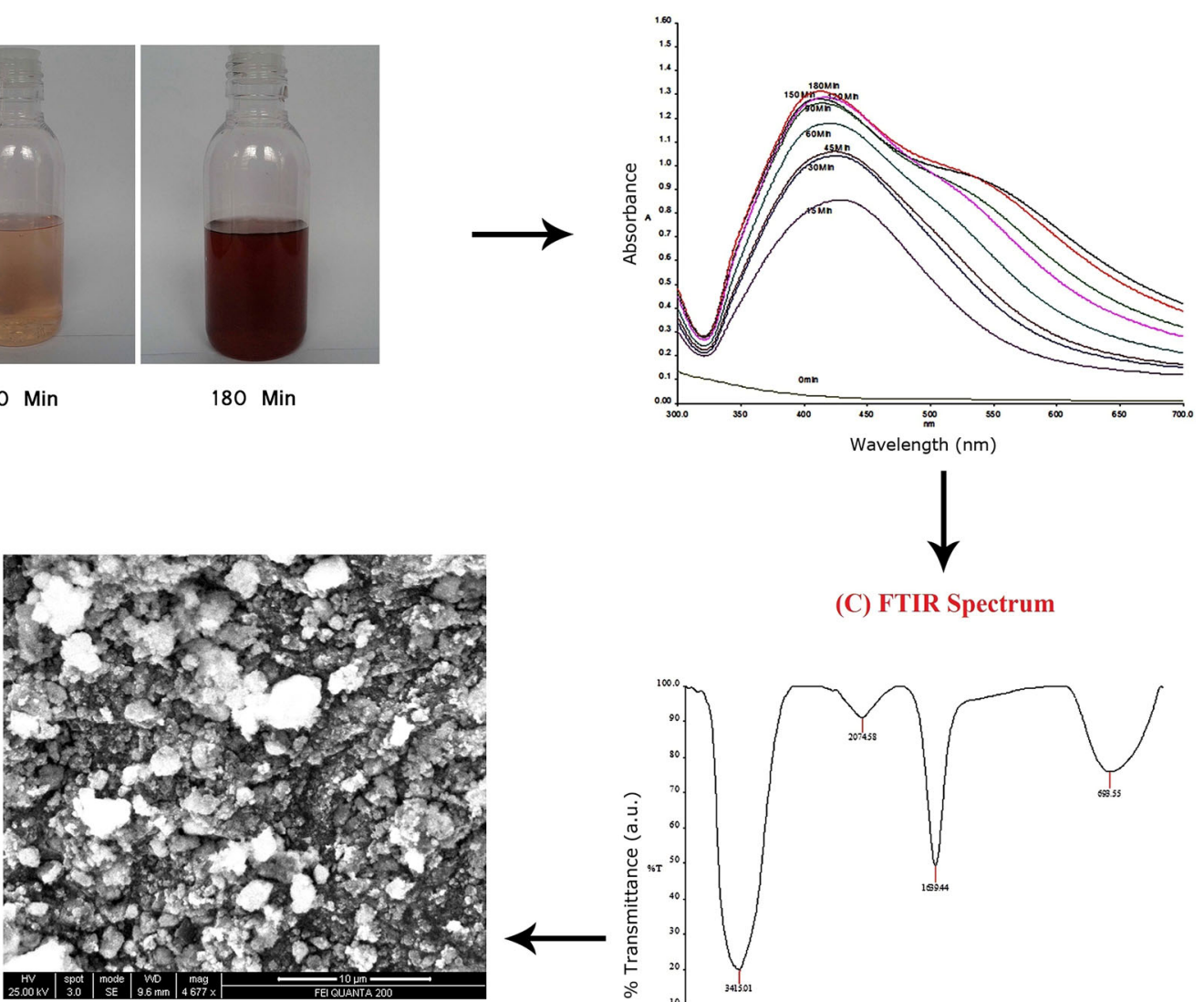

(C) FTIR Spectrum
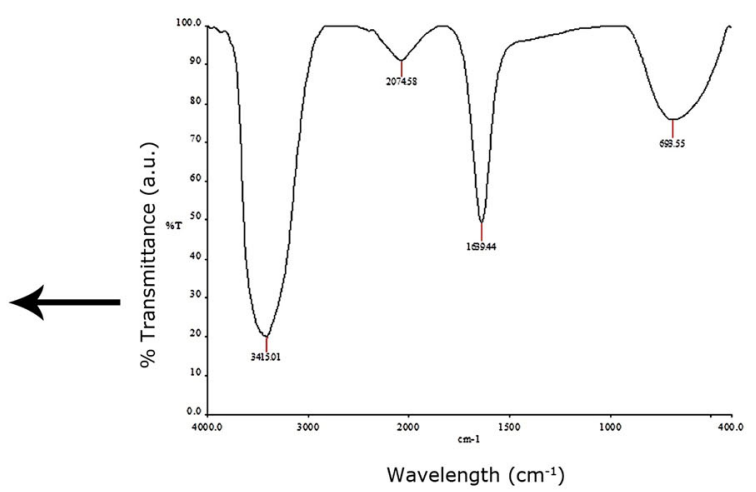

Fig. 2 Color change, UV, FTIR and SEM image of Cycas circinalis (AgNPs) 


\section{Plant Name: Ficus Amplissiama}

\section{(a) Color Change}

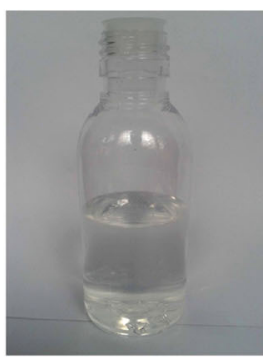

0 Min

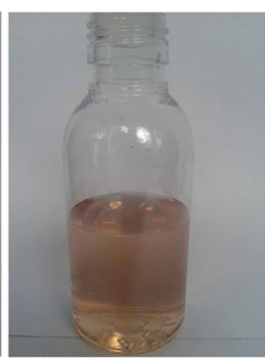

30 Min

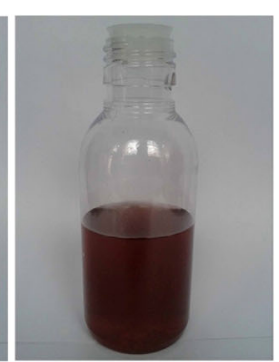

180 Min
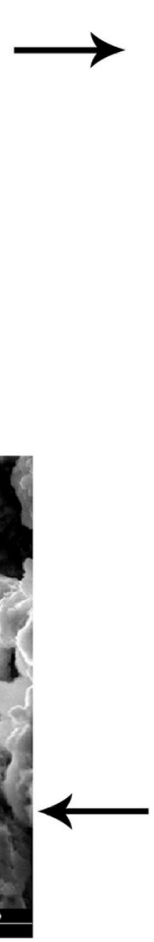

(b) UV Spectrum

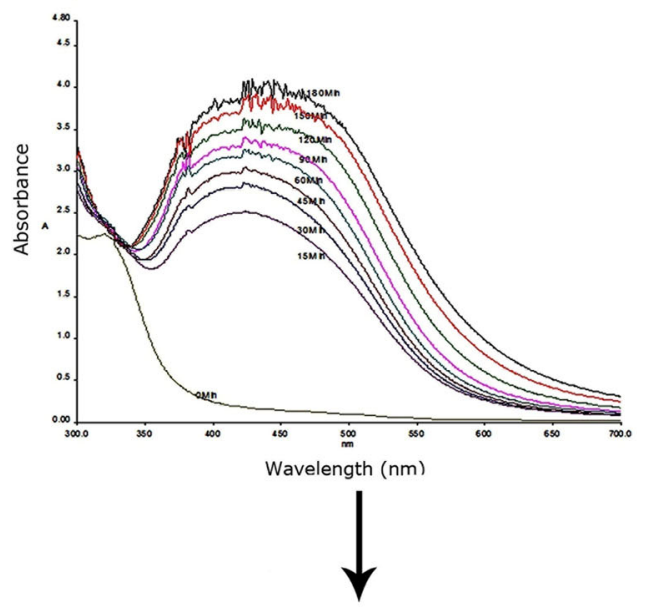

(c) FTIR Spectrum

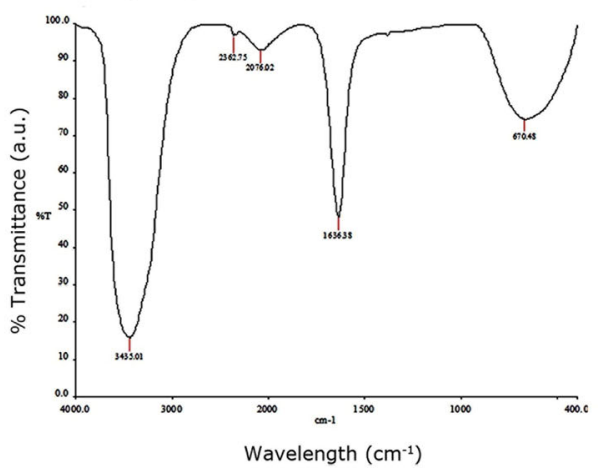

Fig. 3 Color change, UV, FTIR and SEM image of Ficus amplissima (AgNPs)

\section{Results and discussion}

Visual examination

Figures 2, 3, 4 and 5 show the color change of reaction mixture (silver nitrate solution and plant extract) with respect to time. The changes are observed in the period notably from $15 \mathrm{~min}$, from colorless to faint yellow, indicating the formation of AgNPs. As time elapsed, the faint yellow-colored solution eventually became dark brown at $180 \mathrm{~min}$, which is due to the increasing concentration of AgNPs as well as the growth of the number of particles. There is no significant change beyond $210 \mathrm{~min}$; therefore, indicating the completion of the reduction reaction.
UV-visible spectrum analysis

The observation from visual examination was further confirmed by UV-visible spectrum analysis. This physical appearance of the reaction mixture from faint yellow to brown is due to the surface plasmon resonance (SPR) of the AgNPs, which is considered to be the primary signature of the formation of nanoparticles [19].

The UV-visible spectrum of the reaction mixture recorded as a function of time is shown in graph. An observed peak at $423-452 \mathrm{~nm}$ is assigned to the surface plasmon resonance band of the AgNPs, which is comparable with the literature values and exhibits continuous rise in intensity without any change in the peak position as a function of time. During 0-150 min intervals, the 


\section{Plant Name: Commelina Benghalensis}

(a) Color Change

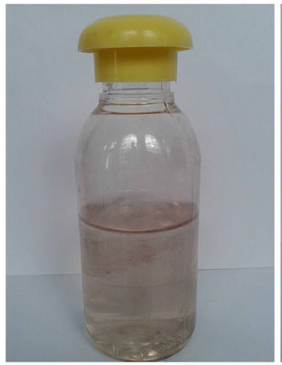

0 Min

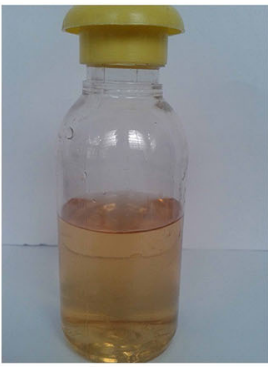

30 Min

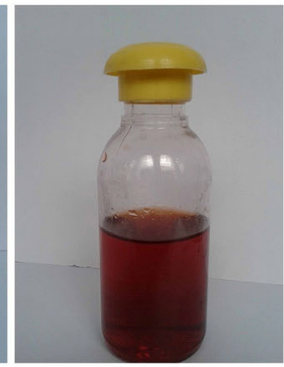

180 Min (b) UV Spectrum

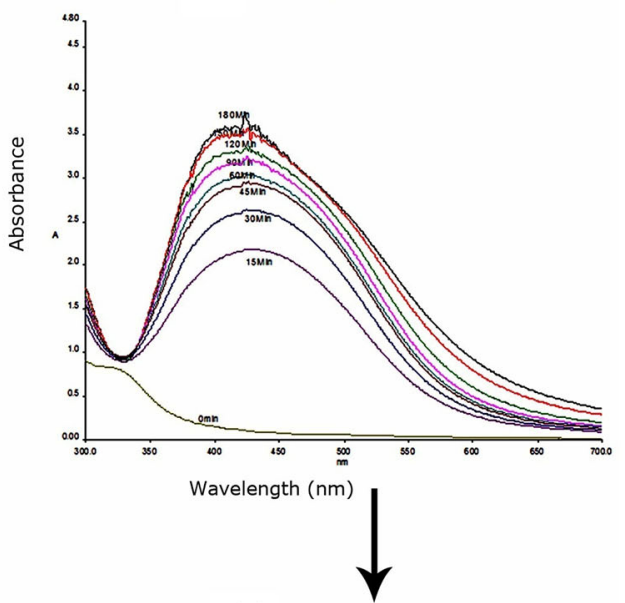

(c) FTIR Spectrum

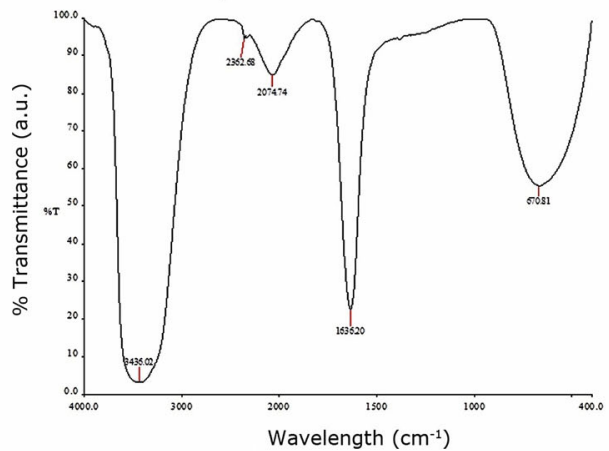

Fig. 4 Color change, UV, FTIR and SEM image of Commelina benghalensis (AgNPs)

absorption peak was weak and broad, which indicates the smaller size of AgNPs. The absorption peaks are found to increase with the time which is in accordance with the color change observed in visual examination [20]. However, the peaks do not last after 180 min which also confirms the observation by visual examination.

\section{FTIR analysis}

FTIR measurement was carried out to identify the possible biomolecules responsible for capping and efficient stabilization of $\mathrm{Ag}$ nanoparticles synthesized using plant extracts. It is used to probe the chemical composition of the surface of the AgNPs and the local molecular environment of the capping agents on the nanoparticles. The FTIR spectrum of silver nanopowder is shown in Figs. 2, 3, 4 and 5. The medium bands at $1,636,1,639,1,636.38$ and $1,637 \mathrm{~cm}^{-1}$ correspond to the amide I band and amide II band appears as a shoulder at $1,574 \mathrm{~cm}^{-1}$. These amide I and amide II bands occur due to carbonyl stretch and $\mathrm{N}-\mathrm{H}$ deformation vibrations in the amide linkage of proteins present in it. Proteins may bind to $\mathrm{Ag}$ nano particles through free amine groups or carboxylate ion of amino acid residue in it. The band at $693.55,670.48,670.81$ and $594.14 \mathrm{~cm}^{-1}$ corresponds to silver metal vibrations. IR spectroscopic study confirmed that the plant extract has the ability to perform dual functions of reduction and stabilization of AgNPs.

Nanoparticles were centrifuged and washed thoroughly in ultrapure water to remove capping agents.

\section{SEM analysis}

Scanning electron microscopy provided further insight into the morphology and size details of the AgNPs. SEM image shows high-density $\mathrm{Ag}$ nanoparticles synthesized by $C$. 


\section{Plant Name: Lippia Nodiflora}

(a) Color Change

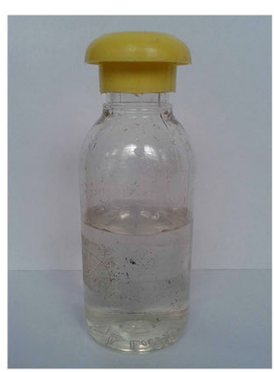

0 Min

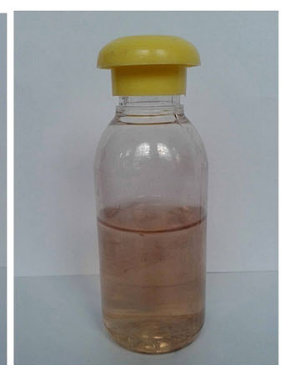

30 Min

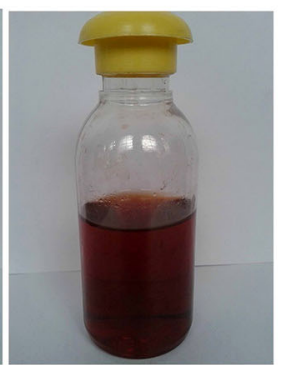

$180 \mathrm{Min}$
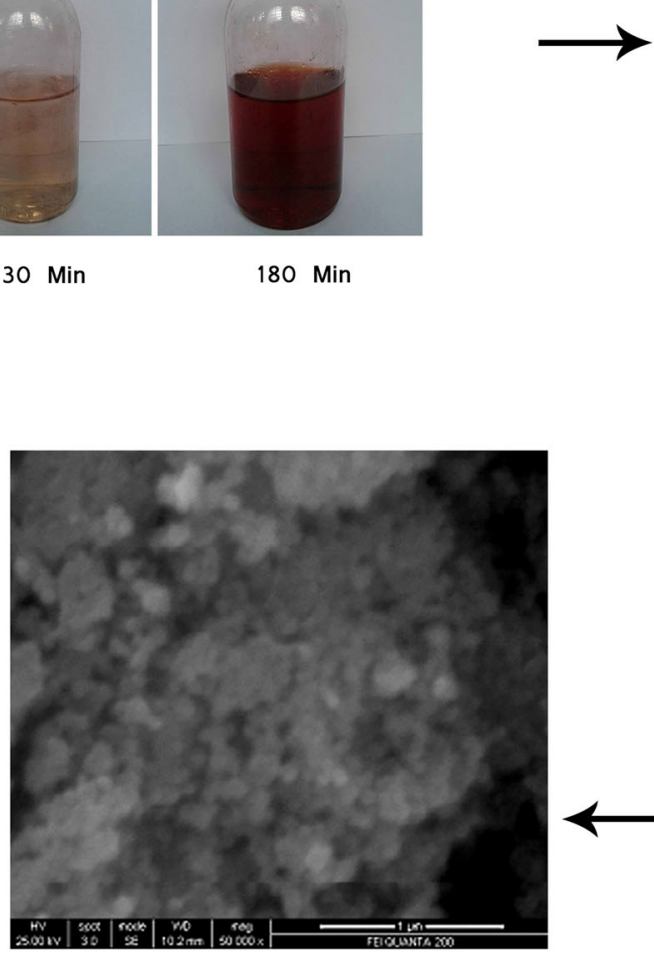

(b) UV Spectrum

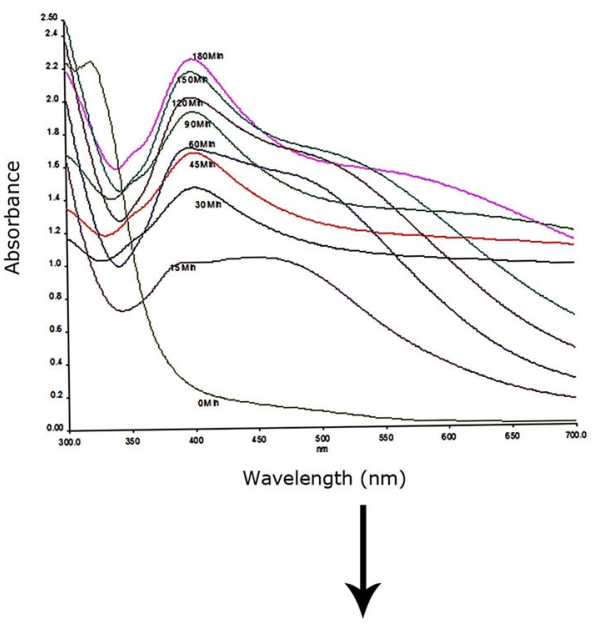

(c) FTIR Spectrum

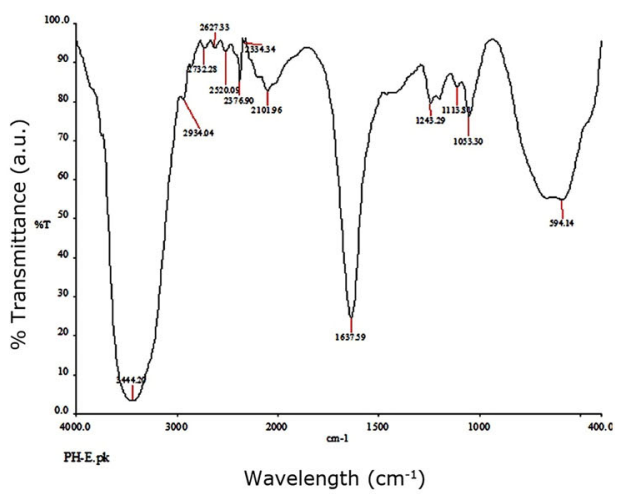

Fig. 5 Color change, UV, FTIR and SEM image of Lippia nodiflora (AgNPs)

circinalis, F. amplissima, C. benghalensis and L. Nodiflora plant extracts and further confirmed the presence of $\mathrm{Ag}$ nanoparticles.

It was shown that relatively spherical and uniform $\mathrm{Ag}$ nanoparticles were formed with diameter of $13-51 \mathrm{~nm}$. In the SEM images, the assembling of AgNPs is shown on the surface.

Figures 2, 3, 4 and 5 show the scanning electron micrographs of AgNPs obtained from the proposed green synthesis (bioreduction) method.

\section{XRD analysis}

The XRD spectra are used to confirm the crystalline nature of the AgNPs synthesized using $C$. circinalis, $F$. amplissima, $C$. benghalensis and $L$. nodiflora and the patterns are exhibited in Fig. 6. The spectra of XRD clearly indicate that the synthesized AgNPs using the above-mentioned extracts are crystalline in nature. They correspond to the lattice planes ( $\left.\begin{array}{lll}1 & 1 & 1\end{array}\right),\left(\begin{array}{lll}2 & 0 & 0\end{array}\right)$ and ( $\left.\begin{array}{lll}2 & 2 & 0\end{array}\right)$ which were indexed for fcc silver. The average sizes of the AgNPs synthesized by leaf extracts of $C$. circinalis, $F$. amplissima, $C$. benghalensis and L. nodiflora are estimated from the Debye-Scherrer equation:

$D=k \lambda / \beta \cos \theta$

where $D$ is the average particle size, $k$ is the shape factor (constant 0.9$), \lambda$ is the X-ray wavelength $(1.5406 \AA), \beta$ is the full width at half maximum of the peak (FWHM) and $\theta$ is the diffraction angle. The average sizes of the AgNPs synthesized by leaf extracts of $C$. circinalis, $F$. amplissima, C. benghalensis and L. nodiflora are around 43, 51, 48 and $32 \mathrm{~nm}$, respectively. 

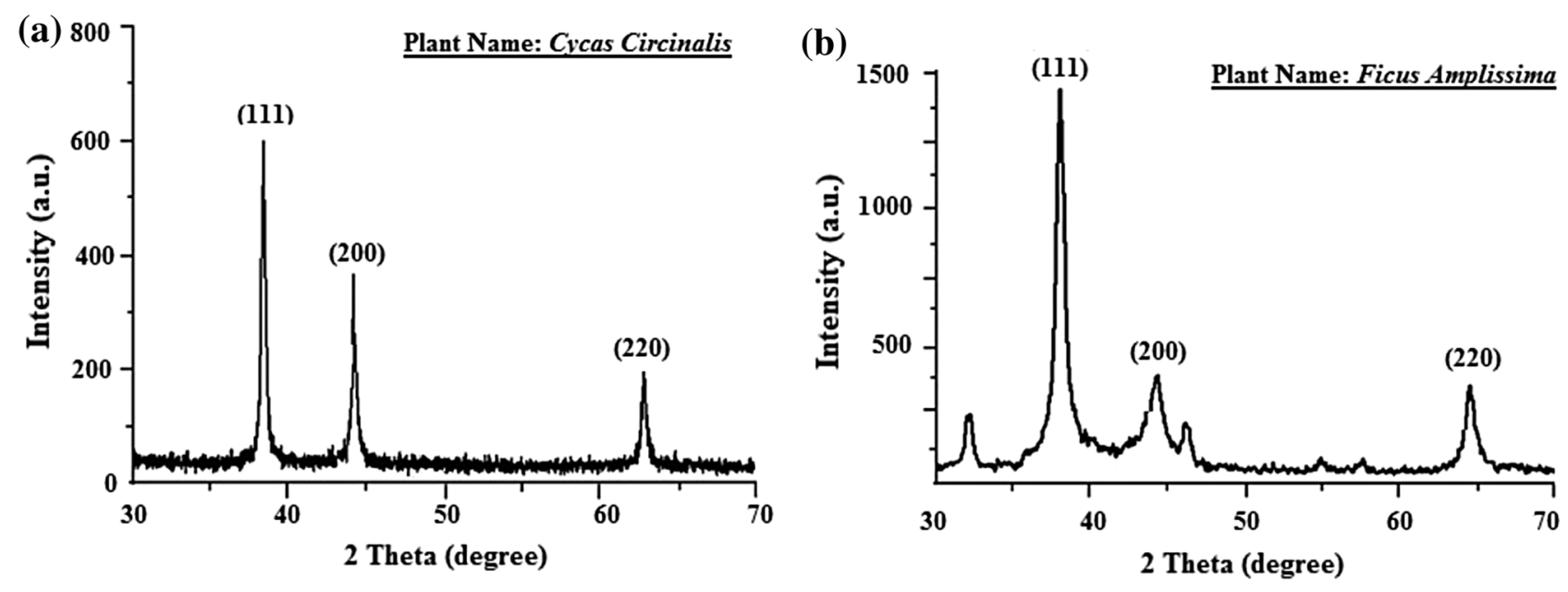

(c)

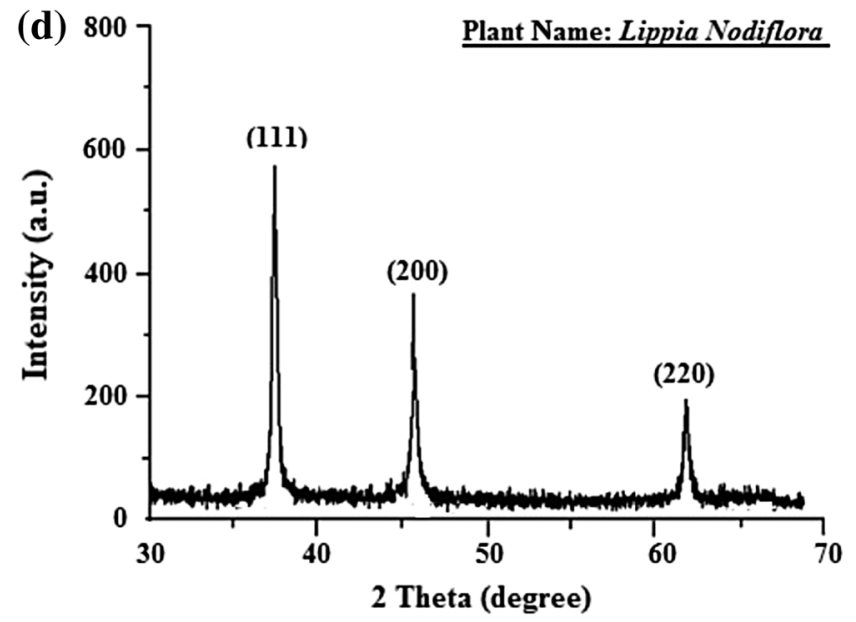

Fig. 6 XRD patterns of nano particles synthesized by the leaf extracts

\section{Conclusion}

Silver nanoparticles were successfully prepared using leaf extracts. The bioreduction of aqueous $\mathrm{Ag}+$ ions by the leaf extracts of the plant has been demonstrated. The reduction of the metal ions through leaf extracts leads to the formation of AgNPs of fairly well-defined dimensions. But the capability of other plant parts such as fruit and root as a capping and reducing agent has not been tested and well defined. In the present study, we found that the leaves of medicinal plants were good source for the synthesis of AgNPs and have many medicinal advantages.

Acknowledgments The authors are thankful to CSIR, New Delhi for its financial assistance in the form of major research project.

Open Access This article is distributed under the terms of the Creative Commons Attribution License which permits any use, distribution, and reproduction in any medium, provided the original author(s) and the source are credited.

\section{References}

1. Narayanan, K.B.: Biological synthesis of metal nanoparticles by microbes. Adv. Colloid Interface Sci. 156, 1-13 (2010)

2. Konwarh, R.: Biomimetic preparation of polymer-supported free radical scavenging, cytocompatible and antimicrobial "green" silver nanoparticles using aqueous extract of Citrus sinensis peel. Colloids Surf. B Biointerfaces 84, 338-345 (2011)

3. Gurunathan, S.: Biosynthesis, purification and characterization of silver nanoparticles using Escherichia coli. Colloids Surf. B Biointerfaces 74, 328-335 (2009)

4. Prathna, T.C.: Biomimetic synthesis of silver nanoparticles by Citrus limon (lemon) aqueous extract and theoretical prediction of particle size. Colloids Surf. B 82, 152-159 (2011)

5. Veerasamy, R.: Biosynthesis of silver nanoparticles using mangosteen leaf extract and evaluation of their antimicrobial activities. J. Saudi Chem. Soc. 15, 113-120 (2011)

6. Kalishwaralal, K.: Biosynthesis of silver and gold nanoparticles using Brevibacterium casei. Colloids Surf. B Biointerfaces 77, 257-262 (2010)

7. Ali, S.A.: Ethnopharmacological activities of the leaves of Cycas circinalis (Cycadaceae). Res. J. Pharm. Biol. Chem. Sci. RJPBCS 2(1), 616 (2011) 
8. Arunachalam, K.: Anti-inflammatory, wound healing and in vivo antioxidant properties of the leaves of Ficus amplissima Smith. J. Ethnopharmacol. 145(1), 139-145 (2013)

9. Mohammad, A., Khan, A.: Antibacterial activity of different fractions of Commelina benghalensis L. Pelagia Res. Libr. Der Pharm. Sin. 2(2), 320-326 (2011)

10. Sharma, R.A.: A review on Phyla nodiflora Linn.: a wild wetland medicinal herb. Int. J. Pharm. Sci. Rev. Res. 20(1), 57-63 (2013)

11. Mason, C.: Switchgrass (Panicum virgatum) extract mediated green synthesis of silver nanoparticles. World J. Nano Sci. Eng. 2, 47-52 (2012)

12. Sahu, N.: Synthesis and characterization of silver nanoparticles using Cynodon dactylon leaves and assessment of their antibacterial activity. Bioprocess. Biosyst. Eng. (2012)

13. Mitra, B.: Green-synthesis and characterization of silver nanoparticles by aqueous leaf extracts of Cardiospermum helicacabum leaves. Drug Invent. Today 4(2), 340-344 (2012)

14. Forough, M.: Biological and green synthesis of silver nanoparticles. In: Nanoscience and Nanotechnology Conference (NanoTRVI), Izmir, 15-18 June 2010 (2010)
15. Philip, D.: Biosynthesis of $\mathrm{Au}, \mathrm{Ag}$ and $\mathrm{Au}-\mathrm{Ag}$ nanoparticles using edible mushroom extract. Spectrochim. Acta Part A 73, 374-381 (2009)

16. Ghodake, G.: Casein hydrolytic peptides mediated green synthesis of antibacterial silver nanoparticles. Colloids Surf. B Biointerfaces 108, 147-151 (2013)

17. Yamini Sudha Lakshmi, G.: Green synthesis of silver nanoparticles from Cleome viscosa: synthesis and antimicrobial activity. In: 2011 International Conference on Bioscience, Biochemistry and Bioinformatics, IPCBEE, Vol. 5. IACSIT Press, Singapore (2011)

18. Johnson, I., Joy Prabu, H., Arulappan, S.: Ultrasound tailoring of industrially important nano particles. Int. J. Sci. Res. Eng. Technol. 2(2), 56-59 (2013)

19. Kalpana, D.: Synthesis and characterization of bactericidal silver nanoparticles using cultural filtrate of simulated microgravity grown Klebsiella pneumoniae. Enzyme Microbial Technol. 52, 151-156 (2013)

20. Wei, D.: The synthesis of chitosan-based silver nanoparticles and their antibacterial activity. Carbohydr. Res. 344, 2375-2382 (2009) 